\title{
Superlatives across domains: Evidence from degree achievements in Southern Aymara*
}

\author{
Gabriel Martínez Vera \\ University of Connecticut
}

\begin{abstract}
This papers proposes that Southern Aymara, an understudied Andean language, has a verbal superlative degree morpheme, namely, $-s u$, that combines with degree achievements. I illustrate this with verbs with -cha, a suffix that derives degree achievements, to which -su attaches. I show that sentences with the verbal superlative -su have absolute and relative readings, which is similar to sentences with adjectival superlatives (as has beed discussed for English). I further show that relative readings arise when the verbal superlative interacts with focus. I propose that verbal superlatives involve comparison of degree-event pairs.
\end{abstract}

Keywords: degree achievement, gradable predicate, superlative, focus, event, Aymara

\section{Introduction}

This paper makes the novel observation that, in Southern Aymara (henceforth, Aymara), there is a verbal superlative, namely, the suffix -su, that combines with degree achievements. I will show that sentences with the verbal superlative in Aymara have absolute and relative readings, which is similar to sentences with adjectival superlatives (as has been discussed for English). I will further show that relative readings arise when the verbal superlative interacts with focus, which in Aymara is marked with the overt focus marker -wa. I will propose that sentences with a verbal superlative involve comparison of degree-event pairs such that the superlative indicates that a given degree is reached in an event such that in no other event is that degree reached. ${ }^{1}$

(1-2) show what sentences with a verbal superlative intuitively mean: in each case, the theme changes in such a way that it reaches the greatest degree-this intuitive meaning is captured by means of the underlined part in the English glosses.

* I would like to especially thank Jon Gajewski and Roger Gonzalo Segura for their constant feedback on this project. This work was supported by the University of Connecticut's El Instituto's Pre-doctoral Fellowship 2017-2018.

1 Typologically, Aymara is a suffixal and to some extent agglutinative language whose sentences show an SOV order. I focus on the dialect of the town of Pomata (province of Chicuito, department of Puno), that is spoken by 13,637 people (Instituto Nacional de Estadística e Informática 2010). 
Thus, in (1), the hair is straightened to a (lexical) maximum (i.e., the hair becomes completely straight); in (2), that table is dirtied to a (contextual) maximum. Throughout this paper, I set aside an extent reading, where the whole or parts of the theme are considered. ${ }^{2,3}$

(1) Mariya ñikut(a)- $\emptyset$ llusk'a-ch(a)-su-(i).

Mary hair-ACC straight-cha-su-3s

'Mary straightened the hair to the greatest degree (of straightness).'

(2) Mariya uka mis(a)- $\emptyset$ qañu-ch(a)-su-(i).

Mary that table-ACC dirty-cha-su-3s

'Mary dirtied that table to the greatest degree (of dirtiness).'

The data discussed in this paper are based on two sources of information: grammatical descriptions, in particular, Cerrón-Palomino (2008) and, for the most part, Gonzalo Segura (2011), and original fieldwork with two consultants. The methodology used for the latter involved the presentation of contextual scenarios using Spanish as an auxiliary language, which was followed by a request for a felicity judgment on a particular grammatical sentence given that contextual scenario (see Matthewson 2004; Davis, Gillon \& Matthewson 2014; and Bochnak \& Matthewson 2015 for discussion regarding the soundness and validity of the aforementioned methodological choices).

The roadmap of this paper is as follows: in section 2, I introduce degree achievements that are derived with the suffix -cha. In section 3, I propose that -su conveys maximality, and address telicity contrasts involving verbs with -cha and -su. In section 4, I provide evidence that suggests that the suffix -su is a degree morpheme. In section 5, I show that sentences with verbal superlatives can have absolute and relative readings - the latter show interaction with focus. Section 6 is the proposal, which I state in terms of comparison of degree-event pairs. Section 7 is the conclusion.

\section{Verbs with -cha}

The suffix -cha derives degree achievements in Aymara. Here I make use of the verbs

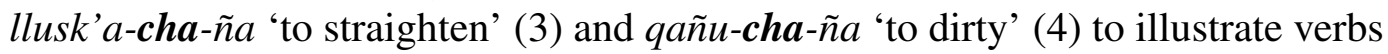
with this suffix-i.e., the verbs that are present in (1-2); - $\tilde{a} a$ is the infinitival marker. The bases in these verbs are llusk'a 'straight' and qañu 'dirty' respectively. Focusing on the verb-theme relation, (3-4) convey the meaning that there is an increase in

2 Abbreviations: $3 \mathrm{~S}=$ third person subject $; \mathrm{ABL}=$ ablative; $\mathrm{ACC}=$ accusative; $\mathrm{DUR}=$ durative $; \mathrm{FOC}=$ focus.

3 Ellided vowels are put in parentheses. 
Superlatives across domains

degree for the theme: in (3), the hair increases in its degree of straightness; in (4), that table increases in its degree of dirtiness.

(3) Mariya ñikut(a)- $\emptyset$ llusk’a-ch(a)-i.

Mary hair-ACC straight-cha-3s

'Mary straightened the hair (i.e., Mary made the hair straighter).'

(4) Mariya uka mis(a)- $\emptyset$ qañu-ch(a)-i.

Mary that table-ACC dirty-cha-3s

'Mary dirtied that table (i.e., Mary made that table dirtier).'

The bases in verbs with - cha in (3-4) are gradable-the suffix -cha derives degree achievements out of gradable base predicates. Following extensive literature on the topic (Cresswell 1976; Kennedy \& McNally 2005; Klein 1991; Pedersen 2015), gradable predicates can be understood in terms of scales $S$. These are sets of linearly ordered degrees $d$ along some dimension associated with a predicate. A scale $S$ is defined as follows:

(5) The scale $S$ associated with a gradable base predicate is a pairing $\langle S,<\rangle$ or $\langle S,>\rangle$, where $<$ or $>$ is a linear order on $S$.

The minimal and maximal degrees in the scale $S$ of a gradable base predicate are defined in (6) - note that if these degrees exist, they are unique (since the scale is linearly ordered):

(6) a. $\min _{S}$, the minimal degree $\in S$, is defined as the degree $d$ such that no degree $d^{\prime}<d$.

b. $\max _{S}$, the maximal degree $\in S$, is defined as the degree $d$ such that no degree $d<d^{\prime}$.

The scale associated with a predicate could lexically incorporate no minimal or maximal degree (these are open scales, which are exemplified (7)), either a minimal or a maximal degree (these are partially closed scales, as in (8)), or both a minimal and a maximal degree (these are closed scales, as in (9)). (7-9) illustrate the same dimensions for each row, i.e., softness/hardness in (7), cleanliness/dirtiness and curliness/straightness (8), and emptiness/fullness in (9), but opposite orderings, as indicated in the parentheses next to each item.

(7) Open scales

soft $\quad(>) \quad$ hard $(<)$

(8) Partially closed scales

a. clean $(>) \quad$ dirty $(<)$ 


$$
\text { b. curly }(>) \quad \text { straight }(<)
$$

\section{(9) Closed scales}

$$
\text { empty }(>) \quad \text { full } \quad(<)
$$

Verbs with - cha are derived with any kind of gradable base, i.e., gradable bases can have any of the scales in (9) associated with them. Thus, the verbs in (10) are derived from bases that have an open scale associated with them, the verbs in (11) are derived from bases that have a partially closed scale associated with them, and the verb in (12) has a closed scale associated with it. Note that examples like those in (10-11) show that there is no restriction with regard to the ordering of the scale: $(10 a-b)$ and (11a-b) are antonyms that involve opposite orderings.

\section{Open scales}

$\begin{array}{llll}\text { a. quña } & \text { 'soft' } & \text { quña-cha-ña } & \text { 'to soften' } \\ \text { b. qala } & \text { 'hard' } & \text { qala-cha-ña } & \text { 'to harden' }\end{array}$

\section{Partially closed scales}
a. llusk'a 'straight'
llusk'a-cha-ña 'to straighten'
b. phirqa 'curly'
phirqa-cha-ña 'to curl'
c. qañu 'dirty'
qañu-cha-ña 'to dirty'

\section{Closed scales}

phuqa 'full' phuqa-cha-ña 'to fill'

In the case of degree achievements, the scales of the base predicates are incorporated by the verb. In particular, as Kennedy \& Levin (2008) discuss, degree achievements have a derived minimum, namely, the degree with which the theme starts out when participating in the change. In this sense, the scale associated with degree achievements is always bottom closed. This is not the case with the degree reached at the end of the change: depending on the scale associated with the base predicate, an absolute maximum may or may not be reached. Thus, if the base has a top-closed scale, a reading of the degree achievement in which an absolute maximum is reached is possible (this is the case of, e.g., to straighten and its Aymara counterpart llusk'a-cha-ña); if the base is top-open, such reading is not available, as the base does not include such maximum (this is case of, e.g., to harden and its Aymara counterpart qala-cha-ña). The issue of reaching a maximum or not is of particular interest in this paper; I turn to it in the next section.

\section{Maximality and telicity contrasts}

In this paper, I propose that $-s u$ conveys maximality, i.e., when -su is added to sentences like (3-4) (i.e., (1-2)), a maximum is conveyed-in the absence of -su, no 
maximum is conveyed (see Martínez Vera 2018 for an account of sentences involving degree achievements with -cha where $-s u$ is not present). Thus, whether the base does or does not provide a (lexical) maximal degree (e.g., llusk'a 'straight' includes it, but qañu 'dirty' does not), -su expresses maximality.

Evidence for this comes from the adjunction of expressions that target low degrees in the scale of the expression under discussion. In Aymara, one such expression is juk'aki 'a little bit': while it is compatible in the absence of -su, it is incompatible in its presence. This is exemplified in (13-14). These examples suggest that a maximum is reached in the presence of $-s u$. It is a lexical one in (13b); it is a contextual one in (14b).

a. Mariya juk'aki ñikut(a)-Ø llusk'a-ch(a)-i.

Mary a little bit hair-ACC straight-cha-3s

'Mary straightened the hair (i.e., Mary made the hair straighter) a little bit.'

b. ?*Mariya juk'aki ñikuta- $\emptyset$ llusk'a-ch(a)-su-(i).

Mary a little bit hair-ACC straight-cha-su-3s

'Mary straightened the hair (to the greatest degree of straightness) a little bit.'

a. Mariya juk'aki uka mis(a)- $\emptyset$ qañu-ch(a)-i.

Mary a little bit that table-ACC dirty-cha-3s

'Mary dirtied that table (i.e., Mary made that table dirtier) a little bit.'

b. ?*Mariya juk'aki uka misa- $\emptyset$ qañu-ch(a)-su-(i).

Mary a little bit that tableACC dirty-cha-su-3s

'Mary dirtied that table (to the greatest degree of dirtiness) a little bit.'

This discussion is relevant with regard to telicity, since there is a clear contrast when sentences involving verbs with - cha are considered. The contrast is crucially tied to the presence or absence of $-s u$. To show this, I make use of the Aymara equivalents of in- and for-adverbials, specifically, the equivalents of in an hour and for an hour. These are distinguished by means of the presence or absence of the ablative suffix -tha, which attaches to the time expression; in particular, the ablative marker is present in telic adverbials but is absent in atelic ones. Of importance here is that, when -su is present, telic adverbials are possible, whereas atelic ones are ungrammatical, as shown in $(15 \mathrm{~b}, 16 \mathrm{~b})$. In contrast, when $-s u$ is absent, atelic adverbials are possible, whereas telic ones are not, as shown in (15a,16a). This further suggests that, in the presence of $-s u$, a bound (a maximum here) is reached; in its absence, no bound is reached.

a. Mariya ma: ura / ??ma: ura-tha ñikuta- $\emptyset$ llusk'a-ch(a)-i. Mary one hour one hour-ABL hair-ACC straight-cha-3S 
'Mary straightened the hair (i.e., Mary made the hair straighter) for an hour/in an hour.'

b. Mariya ?*ma: ura / ma: ura-tha ñikuta- $\emptyset$ llusk'a-ch(a)-su-(i).

Mary one hour one hour-ABL hair-ACC straight-cha-su-3s

'Mary straightened the hair (to the greatest degree of straightness) for an hour/in an hour.'

(16) a. Mariya ma: ura / ??ma: ura-tha uka misa- $\emptyset$ qañu-ch(a)-i.

Mary one hour one hour-ABL that table-ACC dirty-cha-3s

'Mary dirtied that table (i.e., Mary made that table dirtier) for an hour/in an hour.'

b. Mariya ?*ma: ura / ma: ura-tha uka misa- $\emptyset$

Mary one hour one hour-ABL that table-ACC

qañu-ch(a)-su-(i).

dirty-cha-su-3s

'Mary dirtied that table (to the greatest degree of dirtiness) for an hour/in an hour.'

\section{The suffix $-s u$ as a degree morpheme}

In this section, I argue that -su is a degree morpheme. Gonzalo Segura (2011) shows that $-s u$ is a suffix that combines very close to the verbal domain, in fact, it appears right next to the suffix -cha. It precedes all the morphemes that alter the verbal valence, such as the anticausative - $t a$ and the benefactive -rapi. It also precedes aspectual markers. Consider, for example, the durative -ska. This suffix merges after $-s u$ (the durative also combines in the structure after the suffixes that alter the valence of the verb are combined). This distribution is compatible with -su being a degree morpheme, since this kind of element is claimed to combine in a very low position in the structure (Hay, Kennedy \& Levin 1999; Kennedy \& Levin 2008; Pedersen 2015).

The relative position of $-s u$ and $-s k a$ is of particular interest in the present discussion, because it could be argued that, in principle, $-s u$ is some kind of perfect(ive) aspectual marker, since it is closely tied to telic readings, which were discussed in section 3. The expectation would be that these two suffixes would not co-occur, as they would head the same projection (i.e., AspectP). As mentioned above, this is not the case, since both suffixes can actually co-occur, where -su precedes -ska (see Merchant 2015 and references therein for recent discussion with regard to the relative position of AspectP in the syntactic spine). In this regard, consider (17), an example in which -su and -ska appear in the same clause. In this case, the duration of the event of Mary dirtying that table is extended, and it ends reaching a point in which it cannot be dirtied anymore. Under the proposal that -su targets a maximum, 
Superlatives across domains

the presence of this suffix in (17) would mean that a (contextual) maximal degree is reached at the end of the event (as the scale associated with the base qañu 'dirty' does not include a lexical one). The English translation using the progressive tries to make explicit that the duration of the event was extended.

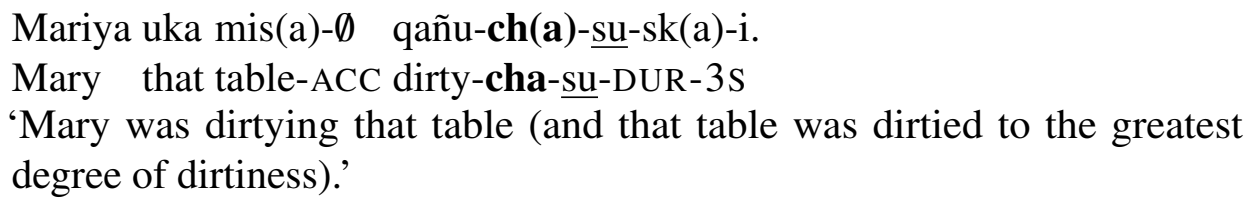

The sentence when -su is absent is also grammatical, as shown in (18). In this case, the duration of the event is also extended. Crucially, (17-18) differ minimally in that a maximal degree is not reached in the latter (since $-s u$ is absent). Note that in both sentences the durative's contribution to the meaning of the sentence is the same: the duration of the event is extended. Thus, this meaning does not compete or replace the contribution of $-s u$.

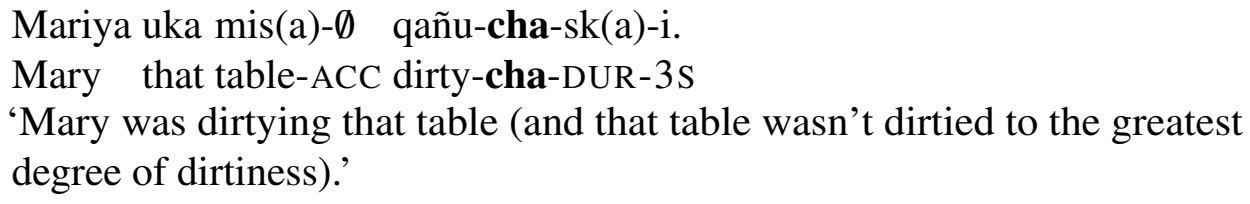

It is also worth pointing out that $-s u$ has a restricted distribution in that it only combines with degree achievements. In connection with this, I discuss two related issues. On the one hand, although in this paper the case under study involves degree achievements derived with the suffix -cha, -su may also combine with other degree achievements, e.g., lexical ones. This is shown in (19). The verb is the lexical degree achievement ch'iyara-ña 'to darken'.
a. Jusiya uka is(i)- $\emptyset$ ch'iyar(a)-i.
Joseph that dress-ACC darken-3s
'Joseph darkened that dress (i.e., Joseph made the dress darker).'
b. Jusiya uka is(i)- $\emptyset$ ch'iyar(a)-su-(i).
Joseph that dress darken-su-3s
'Joseph darkened that dress to the greatest degree (of darkness).'

Moreover, if -su is in fact a degree morpheme, it should not be possible for it to combine with verbs that do not have a degree argument. This is actually the case. I illustrate this with the verb pichawaya-ña 'to sweep', which appears in the examples in (20). The lexical aspect here is that of an activity; interestingly, -su is not allowed in this case. 
a. Jusiya ut(a)- $\emptyset$ pichaway(a)-i.

Joseph house-ACC sweep-3S

'Joseph sweeped the house.'

b. *Jusiya ut(a)- $\emptyset$ pichaway(a)-su-(i).

Joseph house-ACC sweep-su-3s

Intended: 'Joseph swept the house to the greatest degree (of sweepness).'

The discussion in this section thus suggests that $-s u$ is a degree morpheme.

\section{Absolute and relative readings}

This section provides an initial characterization of the readings the suffix -su gives rise to. In this sense, this section provides further details with regard to how the notion of maximality is to be understood in the case under discussion. In particular, I will show that sentences with degree achievements in the presence of -su display an ambiguity between absolute and relative (or comparative) readings-I will only focus on extensional readings here. Relative readings arise under the interaction with focus, which in Aymara is overtly marked with the focus morpheme - wa-in this section, I will concentrate on focalized external and internal arguments. As will be noted, the presence of this ambiguity — including the interaction with focus-is very similar to what has been observed in the literature of adjectival superlatives (Szabolcsi 1986; von Fintel 1994; Heim 1999; Farkas \& Kiss 2000; Sharvit \& Stateva 2002; Stateva 2002; Pancheva \& Tomaszewicz 2012; Tomaszewicz 2015). The discussion to follow will thus mean that the readings associated with adjectival superlatives, which are the ones that have been acknowledged in the semantic literature, are also present in a domain that is distinct from it, in this case, the verbal domain. Based on these parallelisms, I argue that $-s u$ is a verbal superlative.

I will first discuss the so-called absolute reading. In the adjectival domain, this reading can be illustrated with the sentence in (21):

$$
\text { Mary climbed the highest mountain. }
$$

The absolute reading of this sentence is as follows: what was climbed is the highest among mountains (in a relevant context). Suppose that the relevant context includes the highest among mountains, namely, Mount Everest. The absolute reading of (21) means that Mary climbed Mount Everest.

In the case of sentences with a degree achievement and -su in Aymara, recall the sentences in (1-2), repeated below as (22-23). As discussed in section 3, these sentences convey the meaning that the theme changes in such a way that the greatest degree in the relevant scale is reached. Notice that the degrees involved are degrees 
Superlatives across domains

of change. Thus, in the case of (22), the hair is straightened in such a way that the greatest degree of straightness is reached (the degree reached here is lexically encoded in the scale associated with the predicate); in the case of (23), that table is dirtied to the greatest degree of dirtiness (the degree reached here is contextual, as the scale associated with the predicate does not include a lexical maximum).

$$
\begin{aligned}
& \text { Mariya ñikut(a)- } \emptyset \text { llusk'a-ch(a)-su-(i). } \\
& \text { Mary hair-ACC straight-cha-su-3s } \\
& \text { 'Mary straightened the hair to the greatest degree (of straightness).' } \\
& \text { Mariya uka mis(a)- } \emptyset \text { qañu-ch(a)-su-(i). } \\
& \text { Mary that table-ACC dirty-cha-su-3s } \\
& \text { 'Mary dirtied that table to the greatest degree (of dirtiness).' }
\end{aligned}
$$

Under the assumption that degree achievement VPs denote predicates of events, as argued for by, e.g., Kennedy \& Levin (2008), I propose to state the comparison involved in verbal superlatives in terms of events. Thus, with regard to the absolute reading, (22) describes an event of straightening the hair to the greatest degree (a lexical maximum in this case) when compared to other relevant events of straightening the hair in a comparison class in which this is not the case. Something similar can be said with regard to (23): it describes an event of dirtying that table to the greatest degree (a contextual maximum in this case) when compared to other relevant events of dirtying that table in a comparison class in which this is not the case. ${ }^{4}$

I will now turn to the so-called relative (or comparative) reading. The literature on adjectival superlatives points out that this reading appears in the interaction with focus. An example appears in (24). It differs from (21) in that Mary is focalized-the focalized element is marked with $\mathrm{F}$.

$[\text { Mary }]_{F}$ climbed the highest mountain.

The relative reading of this sentence is as follows: Mary need not climb the highest among mountains (i.e., Mount Everest); instead, it suffices that she be the one that climbed the highest mountain among the relevant individuals (in a comparison class) that climbed mountains.

The relative reading of adjectival superlatives is translatable to the verbal domain in Aymara when expressions including $-s u$ are considered. In this language, focalized

4 In this paper, I set aside further issues that arise when events are linked to possible worlds and different times-in principle, it is conceivable that the comparison involves events happening in different worlds or at different times. I will only make reference to an intuitive (and simplified) comparison of events where some degree of change is reached. This is one of the issues that needs to be addressed in future research in order to pin down the details with regard to how the comparison class in expressions with verbal superlatives should be analyzed. 
elements are marked with the overt marker -wa (see Klose 2015 for the suggestion that $-w a$ is a focus marker). ${ }^{5}$ Here I show how $-s u$ interacts with focus when the external and internal arguments are focalized. With regard to the focalization of the external argument, consider the examples in (25-26).

[Mariya-wa] ñikut(a)-Ø llusk'a-ch(a)-su-(i).

Mary-FOC hair-ACC straight-cha-su-3s

'Mary straightened the hair more than anybody else did (i.e., Mary made a greater change in straightness than anybody else did).'

[Mariya-wa] uka mis(a)- $\emptyset$ qañu-ch(a)-su-(i).

Mary-FOC that table-ACC dirty-cha-su-3s

'Mary dirtied that table more than anybody else did (i.e., Mary made a greater change in dirtiness than anybody else did).'

Here the external argument is focalized. (25) conveys the meaning that Mary straightened the hair more than anybody else did, which crucially means that the hair need not be fully straight as a result of Mary's straightening of the hair. In terms of events, (25) describes an event in which Mary's straightening of the hair reached some degree (not necessarily the maximum) and nobody else straightened the hair as much as Mary. Something similar can be said with regard to (26): it conveys the meaning that Mary dirtied that table more than anybody else-no maximum need be reached. In terms of events, (26) describes an event in which Mary's dirtying of that table reached some degree (not necessarily a contextual maximum) and nobody else dirtied that table as much as Mary.

The sentences in (27-28) show the case where the internal argument (the theme) is focalized:

\section{Mariya [ñikut(a)-( -wa] llusk'a-ch(a)-su-(i).}

Mary hair-ACC-FOC straight-cha-su-3s

'Mary straightened the hair more than anything else (i.e., the change in straightness of the hair is greater than the change in straightness of anything else).'

$$
\text { Mariya [uka mis(a)-(Ø-wa] qañu-ch(a)-su-(i). }
$$

Mary that table-ACC-FOC dirty-cha-su-3s

'Mary dirtied that table more than anything else (i.e., the change in dirtiness of that table is greater than the change in dirtiness of anything else).'

The reasoning with regard to the relative reading in this case is similar to what was discussed for (25-26). What is crucial in the examples is that the theme is

5 The focus marker -wa has an empty allomorph when it appears next to the theme in some dialects of Aymara. 
Superlatives across domains

straightened (27) or dirtied (28) more than anything else-crucially, no maximum need be reached. Thus, (27) describes an event of Mary's straightening of the hair in which some degree (not necessarily the maximum) is reached and no other thing was straightened to that degree. (28) describes an event of Mary's dirtying of that table in which some degree (not necessarily the maximum) is reached and no other thing was dirtied to that degree.

To sum up, this section has shown that sentences with -su in Aymara display the ambiguities that have been reported in the literature for adjectival superlatives. Based on this, I propose that $-s u$ is a verbal superlative.

\section{Proposal}

This section spells out my proposal. In subsection 6.1 , I briefly address what kind of analysis for the verbal superlative I will pursue and make my assumptions explicit; I further propose the denotation of $-s u$. In subsection 6.2, I discuss how absolute readings are achieved. In subsection 6.3, I turn to relative readings, which involve discussion of the interaction of the verbal superlative with focus.

\subsection{Setup and assumptions}

I will pursue an analysis that follows Heim (1999) (see also Pancheva \& Tomaszewicz Pancheva \& Tomaszewicz; Tomaszewicz 2015 for recent analyses in a similar vein), i.e., an analysis involving movement of the superlative morpheme at L(ogical) F(orm) - in principle, an in situ analysis can also be pursued; the purpose here is more modest, namely, to provide an initial analysis that derives the properties discussed in the previous sections.

Restricting the account to the verbal domain, which here involves the highest projection within $v \mathrm{P} / \mathrm{VP}$ and, I assume, includes the landing site of $-s u$, the LFs I assume appear in (29-30). The LF in (29) is the one I assume is present to derive absolute readings; the LFs in (30) are the ones I assume are present to derive relative readings - the LFs in (30) vary depending on which argument is focalized; I will adopt an approach to focus which follows Rooth (1992) et seq., as will be made explicit in subsection 6.3. I assume that the external argument is an agent, which is introduced by little $v$ (Kratzer 1996), that movement of -su leaves a trace $t \in D_{d}$, and that $\mathrm{C}$ is a comparison class, which is formed by degree-event pairs-in the LFs, Ag $=$ agent, $\mathrm{F}=$ focus, $\mathrm{P}=$ gradable base, $\mathrm{Th}=$ theme .

$$
\left[\left[\lambda d\left[{ }_{\nu \mathrm{P}} \mathrm{Ag}\left[\left[[\mathrm{vP} \mathrm{Th}[\mathrm{P}-\mathrm{cha}]] \mathrm{t}_{d}\right] v\right]\right]\right][\mathrm{C}-\mathrm{su}]\right]
$$

$$
\begin{array}{ll}
\text { a. } & {\left[\left[\left[\lambda d\left[{ }_{v \mathrm{P}} \operatorname{Ag}_{\mathrm{F}}\left[\left[[\mathrm{vP} \mathrm{Th}[\mathrm{P}-\mathrm{cha}]] \mathrm{t}_{d}\right] v\right]\right]\right] \sim \mathrm{C}\right][\mathrm{C}-\mathrm{su}]\right]} \\
\text { b. } & {\left[\left[\left[\lambda d\left[{ }_{\nu \mathrm{P}} \operatorname{Ag}\left[\left[\left[\mathrm{vP} \mathrm{Th}_{\mathrm{F}}[\mathrm{P}-\mathrm{cha}]\right] \mathrm{t}_{d}\right] v\right]\right]\right] \sim \mathrm{C}\right][\mathrm{C}-\mathrm{su}]\right]}
\end{array}
$$


In this subsection, I will focus on the compositional setup up to the $v \mathrm{P}$ node, i.e., to the part of the LF in (31) (which is common to both (29-30)), and will propose what the denotation of $-s u$ is. In the next subsections, I will focus on how to derive the absolute and relative readings discussed in section 5.

$$
\left[{ }_{v \mathrm{P}} \mathrm{Ag}\left[\left[[\mathrm{vP} \mathrm{Th}[\mathrm{P}-\mathrm{cha}]] \mathrm{t}_{d}\right] v\right]\right]
$$

I will first discuss my assumptions with regard to gradable bases and degree achievements. I assume that gradable base predicates denote relations of type $\langle d,\langle e, i t\rangle\rangle$ ( $i$ is the type of events) which are true of degree $d$, individual $x$ and event $e$ iff $x$ holds $d$ in the scale of the base in $e$ (von Stechow 1984; Heim 1985; Bierwisch 1989; Klein 1991; Kennedy \& McNally 2005; Kennedy \& Levin 2008)—I assume that $d$ is held constant throughout the run time of $e$ (Morzycki 2015). I provide examples with the bases used throughout this paper, namely, llusk'a 'straight' (32)

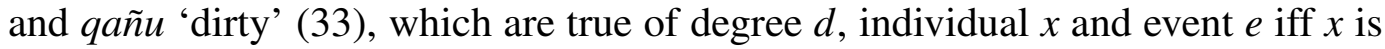
$d$-straight and $d$-dirty (respectively) in $e$.

$$
\begin{aligned}
& \llbracket \text { llusk'a } \rrbracket=\lambda d \lambda x \lambda e[\operatorname{straight}(x, d, e)] \\
& \llbracket \mathbf{q a n ̃ u} \mathbf{u} \rrbracket=\lambda d \lambda x \lambda e[\operatorname{dirty}(x, d, e)]
\end{aligned}
$$

Within the approach that assumes that gradable bases denote relations, which is the one I adopt here, I adapt Kennedy \& Levin's (2008) proposal for degree achievements, in particular, I assume that the core meaning of degree achievements is derived from gradable bases, but, instead of assuming that degree achievements denote differential measure functions representing the amount to which an individual changes in an event, I assume that they denote relations such that an individual holds a degree of change in an event. This is stated in (34). Informally, (34) says that the relation $P_{\Delta}$, which is derived from any gradable base $P$, is true of individual $x$, degree $d$ and event $e$ iff $x$ holds $d$ in $e$, where $d$ is less than or equal to the non-zero subtraction of the degree of $P x$ holds at the end of $e$ minus the degree of $P x$ holds at the beginning of $e$. As anticipated in section 2, degree achievements (which denote relation $P_{\Delta}$ ) will include a scale that is top-closed or top-open depending on the scale of the base. In what follows, I also use $P$ for variables of type $\langle d,\langle e, i t\rangle\rangle$ (i.e., the type of gradable bases); I use $P_{\Delta}$ for variables of type $\langle d$, it $\rangle$ in addition to using it to refer to degree achievements (with partially saturated arguments), the commonality being that there is a degree of change involved.

(34) For any gradable base $P$, there is a derived $P_{\Delta}$ such that for any individual $x$, degrees $d, d^{\prime}, d^{\prime \prime}$ and event $e, P_{\Delta}(x, d, e)$ holds iff $P\left(x, d^{\prime}, \operatorname{ini}(e)\right)$ $\& P\left(x, d^{\prime \prime}\right.$, fin $\left.(e)\right) \& d^{\prime}<d^{\prime \prime} \& d^{\prime \prime}-d^{\prime} \geq d$. 
Superlatives across domains

I further assume that the relation $P_{\Delta}$ is downward monotonic (see, among others, Heim 1999 for downward monotonicity of gradable base predicates), i.e., for any individual $x$, degrees (of change) $d, d^{\prime}$ and event $e$, if $P_{\Delta}$ holds of $x, d$ and $e$, and $d^{\prime}$ is less than $d$, then $d^{\prime}$ is also held by $x$ in $e$. This is captured in (35).

A relation $P_{\Delta}$ between individuals, degrees and events is downward monotonic iff for any individual $x$, degrees (of change) $d, d^{\prime}$ and event $e, P_{\Delta}(x, d, e)$ $\& d^{\prime}<d \rightarrow P_{\Delta}\left(x, d^{\prime}, e\right)$.

In the case of Aymara, I further assume that the suffix -cha derives degree achievements from gradable bases (Martínez Vera 2018; see also Hay et al. 1999; Pedersen 2015). Specifically, I propose that the denotation of -cha is as in (36). (36) is true of gradable base $P$, individual $x$, degree $d$ and event $e$ iff $x$ holds $d$ in $e$, where $d$ represents the amount to which $x$ changed along the scale of $P$.

$$
\llbracket \text {-cha } \rrbracket=\lambda P \lambda x \lambda d \lambda e\left[P_{\Delta}(x, d, e)\right]
$$

For illustration, recall the examples in (1-2), which are repeated below. I include the LFs of the respective $v$ Ps as well-in the LFs to follow, I use English words for ease of exposition.
a. Mariya ñikut(a)-Ø llusk'a-ch(a)-su-(i).
Mary hair-ACC straight-cha-su-3s
'Mary straightened the hair to the greatest degree (of straightness).'
b. $\quad\left[v \mathrm{P}\right.$ Mary $\left[\left[[\mathrm{vP}\right.\right.$ the hair [straight -cha] $\left.\left.\left.] \mathrm{t}_{d}\right] v\right]\right]$
a. Mariya uka mis(a)- $\emptyset$ qañu-ch(a)-su-(i).
Mary that table-ACC dirty-cha-su-3s
'Mary dirtied that table to the greatest degree (of dirtiness).'
b. $\quad\left[{ }_{v \mathrm{P}}\right.$ Mary $\left[\left[[\mathrm{vP}\right.\right.$ that table $[$ dirty $\left.\left.\left.-\mathrm{cha}]] \mathrm{t}_{d}\right] v\right]\right]$

The degree achievements in (37-38) are illustrated in (39-40): -cha combines with the bases to derive degree achievements.

$$
\begin{aligned}
& \llbracket \text {-cha } \rrbracket(\llbracket \text { llusk'a } \rrbracket)=\lambda x \lambda d \lambda e\left[\operatorname{straight}_{\Delta}(x, d, e)\right] \\
& \llbracket \text {-cha } \rrbracket(\llbracket \text { qañu } \rrbracket)=\lambda x \lambda d \lambda e\left[\operatorname{dirty}_{\Delta}(x, d, e)\right]
\end{aligned}
$$

Setting aside some fairly standard details involved in the calculation under this approach, ${ }^{6}$ the denotations of $(37 \mathrm{~b}, 38 \mathrm{~b})$ are as in (41-42) respectively.

$6 \mathrm{ag}$ stands for the agentive relation which is true of individual $x$ and event $e$ iff $x$ is the agent of $e$ (see Kratzer 1996 for further details, in particular, for details with regard to how it is possible to combine the agent in LFs as in (37b,38b) by means of Event Identification). 


$$
\begin{aligned}
& \llbracket(37 \mathbf{b}) \rrbracket=\lambda d \lambda e\left[\operatorname{ag}(m, e) \& \operatorname{straight}_{\Delta}(h, d, e)\right] \\
& \llbracket(\mathbf{3 8 b}) \rrbracket=\lambda d \lambda e\left[\operatorname{ag}(m, e) \& \operatorname{dirty}_{\Delta}(t, d, e)\right]
\end{aligned}
$$

Within this setup, I now turn to the denotation -su, which is stated in (43). Specifically, I propose that $-s u$ is a verbal superlative involving comparison of relations of degrees and events where degree (of change) $d$ of $P_{\Delta}$ in event $e$ is not held in any other degree-event pair $\left\langle d, e^{\prime}\right\rangle$ in comparison class $X$.

$$
\llbracket-\mathbf{s u} \rrbracket=\lambda X \lambda P_{\Delta} \lambda e \exists d\left[P_{\Delta}(d, e) \& \forall e^{\prime}\left[e \neq e^{\prime} \&\left\langle d, e^{\prime}\right\rangle \in X \rightarrow \neg P_{\Delta}\left(d, e^{\prime}\right)\right]\right]
$$

\subsection{Absolute readings}

Recall the LF in (29) (repeated below), which, as anticipated, is the one present to yield absolute readings.

$$
\left[\left[\lambda d\left[v \mathrm{P} \operatorname{Ag}\left[\left[[\mathrm{vP} \text { Th }[\mathrm{P}-\mathrm{cha}]] \mathrm{t}_{d}\right] v\right]\right]\right][\mathrm{C}-\mathrm{su}]\right]
$$

To show how I account for this reading, recall the LFs of the $v$ Ps of $(37 \mathrm{a}, 38 \mathrm{a})$ in $(37 b, 38 b)$. In (45-46), I incorporate the binder of the degree trace, the comparison class and $-s u$.

$$
\left.\left.\left[\left[\lambda d{ }_{\nu \mathrm{P}} \text { Mary }\left[[[\mathrm{vP} \text { the hair [straight -cha }]] \mathrm{t}_{d}\right] v\right]\right]\right][\mathrm{C}-\mathrm{su}]\right]
$$$$
\left[\left[\lambda d\left[{ }_{\nu \mathrm{P}} \text { Mary }\left[\left[[\mathrm{vP} \text { that table }[\text { dirty }-\mathrm{cha}]] \mathrm{t}_{d}\right] v\right]\right]\right][\mathrm{C}-\mathrm{su}]\right]
$$

Each of these LFs represent a different case, namely, (45) illustrates the case where the gradable base in the derived verb has a top-closed scale, whereas (46) illustrates the case where the gradable base in the derived verb has a top-open scale. The denotation of (45) appears in (47). (45) is true of event $e$ iff Mary straightened the hair to some degree (of change) $d$ such that $d$ is not reached in any other event $e^{\prime}$ in which Mary straightened the hair. Here the comparison class $X$ equals $\mathrm{C}$, i.e., this is the case in which the comparison class remains (fairly) unrestricted.

$$
\begin{aligned}
\llbracket(45) \rrbracket=\lambda e \exists d\left[a g(m, e) \& \operatorname{straight}_{\Delta}(h, d, e) \&\right. \\
\left.\forall e^{\prime}\left[e \neq e^{\prime} \&\left\langle d, e^{\prime}\right\rangle \in X \rightarrow \neg\left[\operatorname{ag}\left(m, e^{\prime}\right) \& \operatorname{straight}_{\Delta}\left(t, d, e^{\prime}\right)\right]\right]\right]
\end{aligned}
$$

It is important to point out that the denotation in (47) does not guarantee that the maximum of straightness is reached, which is the degree that is reached by default according to intuitions. To make sure that this is the case, I follow Kennedy \& Levin (2008) (see also Kennedy 2007) who claim that, in expressions including degree achievements with a top-closed scale, there is a pragmatic principle that ensures that the maximum is reached in events of change whenever the scale of the predicate includes it. This is the principle of Interpretive Economy, which is stated in (48). 
Superlatives across domains

This guarantees that the maximum is reached whenever it is encoded lexically, which is the case in the example under discussion. ${ }^{7}$ It is worth pointing out that the use of this principle here is somewhat different from the authors' initial intention: for them Interpretive Economy regulates the selection of a standard; here Interpretive Economy regulates how the comparison class for the verbal superlative is formed (in particular, it excludes events in which a degree of change to a maximum is reached).

\section{Interpretive Economy}

Maximize the contribution of the conventional meanings of the elements of a sentence to the computation of its truth conditions.

The case of (46) is similar to the one in (45) in that, in (46), there is an event in which Mary dirtied that table to some degree (of change) and there is no other event in which that degree was reached. Here, again, the comparison class $X$ equals $\mathrm{C}$. The denotation of (46) appears in (49).

$$
\begin{aligned}
& \llbracket(\mathbf{4 6}) \rrbracket=\lambda e \exists d[ {\left[\operatorname{ag}(m, e) \& \operatorname{dirty}_{\Delta}(t, d, e) \&\right.} \\
&\left.\forall e^{\prime}\left[e \neq e^{\prime} \&\left\langle d, e^{\prime}\right\rangle \in X \rightarrow \neg\left[\operatorname{ag}\left(m, e^{\prime}\right) \& \operatorname{dirty}_{\Delta}\left(t, d, e^{\prime}\right)\right]\right]\right]
\end{aligned}
$$

What is different between (45-46) is that, in the latter, the scale is top-open, whereas it is top-closed in the former. This means that, in the latter, a contextual maximum is reached-as discussed above, a lexical maximum is reached in the former. More generally, this means that Interpretive Economy does not apply in cases in which the scale of the predicate is top-open.

\subsection{Relative readings}

Relative readings in verbal superlatives arise when there is interaction with focus, which, as discussed in section 5, is marked by means of -wa in Aymara. Here I adopt Rooth's (1992) approach to focus and adapt it in terms of degree-event relations, which in this case involves focus association by means of the $\sim$ operator-as is wellknown, focus association under this approach involves the presence of alternatives. ${ }^{8}$ In particular, under this approach, expressions have an ordinary value $o$ and a focus value $f$. The former corresponds with the standard meaning of the expression under consideration and the latter is the set of degree-event alternatives. In the cases under

7 Note that this is different from adjectival superlatives: in cases like (i), no maximum of straightness need be reached.

(i) The man bought the straightest rod.

I leave a detailed contrast between verbal and adjectival superlatives for future research. 8 The literature on focus is extensive. See Rooth (2016) for a recent take on it. 
consideration, the focus value is tied to the (focalized) NP: here I have considered focalized external (agent) and internal (theme) arguments- the focus alternatives will vary depending on which NP is focalized.

Below I repeat the LFs in (30a-b) that are present to yield relative readings. The focalized argument in (50a) is the agent; the focalized argument in (50b) is the theme.

$$
\begin{array}{ll}
\text { a. } & {\left[\left[\left[\lambda d\left[{ }_{v} \mathrm{P} \operatorname{Ag}_{\mathrm{F}}\left[\left[[\mathrm{vP} \mathrm{Th}[\mathrm{P}-\mathrm{cha}]] \mathrm{t}_{d}\right] v\right]\right]\right] \sim \mathrm{C}\right][\mathrm{C}-\mathrm{su}]\right]} \\
\text { b. } & {\left[\left[\left[\lambda d\left[{ }_{\nu} \mathrm{P} \operatorname{Ag}\left[\left[\left[\mathrm{vP} \mathrm{Th}_{\mathrm{F}}[\mathrm{P}-\mathrm{cha}]\right] \mathrm{t}_{d}\right] v\right]\right]\right] \sim \mathrm{C}\right][\mathrm{C}-\mathrm{su}]\right]}
\end{array}
$$

To illustrate relative readings of verbal superlatives in Aymara, I will first address the case in which the external argument is focalized. In this regard, recall examples (25-26), which are repeated below. I also include their LFs.

\section{a. [Mariya-wa] ñikut(a)- $\emptyset$ llusk'a-ch(a)-su-(i).}

Mary-FOC hair-ACC straight-cha-su-3s

'Mary straightened the hair more than anybody else did (i.e., Mary made a greater change in straightness than anybody else did).'

b. $\quad\left[\left[\left[\lambda d\left[{ }_{\nu \mathrm{P}}\right.\right.\right.\right.$ Mary $\left[\left[\left[\mathrm{vP}_{\mathrm{P}}\right.\right.\right.$ the hair [straight -cha $\left.\left.\left.\left.\left.\left.\left.]\right] \mathrm{t}_{d}\right] v\right]\right]\right] \sim \mathrm{C}\right][\mathrm{C}-\mathrm{su}]\right]$

a. [Mariya-wa] uka mis(a)- $\emptyset$ qañu-ch(a)-su-(i).

Mary-FOC that table-ACC dirty-cha-su-3s

'Mary dirtied that table more than anybody else did (i.e., Mary made a greater change in dirtiness than anybody else did).'

b. $\quad\left[\left[\left[\lambda d\left[{ }_{\nu \mathrm{P}}\right.\right.\right.\right.$ Mary $\left[[[\mathrm{vP}\right.$ that table [dirty -cha $\left.\left.\left.\left.\left.\left.]] \mathrm{t}_{d}\right] v\right]\right]\right] \sim \mathrm{C}\right][\mathrm{C}-\mathrm{su}]\right]$

Of relevance for the discussion is that the external argument is focalized. In terms of focus association, what this means is that the expressions in (51-52), in addition to an ordinary value-which is as stated in (41-42) in subsection 6.1 and appears below in $(53 a, 54 a)$ for $(51 b, 52 b)$ respectively-have a focus value, which involves individual alternatives, i.e., it involves different individuals straightening the hair (53b) and dirtying the table (54b).

$$
\begin{array}{ll}
\text { a. } & \llbracket(\mathbf{5 1 b}) \rrbracket^{o}=\lambda d \lambda e\left[\operatorname{ag}(m, e) \& \text { straight }_{\Delta}(h, d, e)\right] \\
\text { b. } & \llbracket(\mathbf{5 1 b}) \rrbracket^{f}=\left\{\lambda d \lambda e\left[\operatorname{ag}(x, e) \& \text { straight }_{\Delta}(h, d, e) \mid x \in D_{e}\right\}\right. \\
\text { a. } & \llbracket(\mathbf{5 2 b}) \rrbracket^{o}=\lambda d \lambda e\left[\operatorname{ag}(m, e) \& \operatorname{dirty}_{\Delta}(t, d, e)\right] \\
\text { b. } & \llbracket(\mathbf{5 2 b}) \rrbracket^{f}=\left\{\lambda d \lambda e\left[\operatorname{ag}(x, e) \& \operatorname{dirty}_{\Delta}(t, d, e) \mid x \in D_{e}\right\}\right.
\end{array}
$$

The relative reading arises in connection with the focus alternatives in $(53 \mathrm{~b}, 54 \mathrm{~b})$ these include the original values in $(53 \mathrm{a}, 54 \mathrm{a})$ as one of the alternatives. Comparison class $X$ is a subset of these sets (Heim 1999). Under this approach, it suffices that Mary straightened the hair more than anybody else (51) and that Mary dirtied that 
table more than anybody else (52). Crucial here is that a maximum need not be reached, as long as the degree (of change) to which Mary straightened the hair or Mary dirtied that table is greater than any other degree to which the hair was straightened or that table was dirtied by anybody else.

I now turn to the case in which the theme is focalized, which is, mutatis mutandis, parallel to the case in which the external argument is focalized. Recall examples (27-28), which are repeated below. I also include their LFs.

a. Mariya [ñikut(a)- $\emptyset$-wa] llusk'a-ch(a)-su-(i).

Mary hair-ACC-FOC straight-cha-su-3s

'Mary straightened the hair more than anything else (i.e., the change in straightness of the hair is greater than the change in straightness of anything else).'

b. $\quad\left[\left[\left[\lambda d\left[{ }_{\nu \mathrm{P}}\right.\right.\right.\right.$ Mary $\left[\left[[\mathrm{vP}\right.\right.$ the hair $[$ [straight -cha $\left.\left.\left.\left.\left.\left.]] \mathrm{t}_{d}\right] v\right]\right]\right] \sim \mathrm{C}\right][\mathrm{C}-\mathrm{su}]\right]$

a. Mariya [uka mis(a)- $\emptyset$-wa] qañu-ch(a)-su-(i).

Mary that table-ACC-FOC dirty-cha-su-3s

'Mary dirtied that table more than anything else (i.e., the change in dirtiness of that table is greater than the change in dirtiness of anything else).'

b. $\quad\left[\left[\left[\lambda d\left[{ }_{\nu \mathrm{P}}\right.\right.\right.\right.$ Mary $\left[\left[[\mathrm{vP}\right.\right.$ that table $\mathrm{F}[$ dirty $\left.\left.\left.\left.\left.\left.-\mathrm{cha}]] \mathrm{t}_{d}\right] v\right]\right]\right] \sim \mathrm{C}\right][\mathrm{C}-\mathrm{su}]\right]$

What is relevant here is that the internal argument is focalized. In addition to an ordinary value-which is as stated in (41-42) in subsection 6.1 and appears below in $(57 \mathrm{a}, 58 \mathrm{a})$ for $(55 \mathrm{~b}, 56 \mathrm{~b})$ respectively - $(55-56)$ have a focus value, which involves individual alternatives, i.e., it involves Mary straightening (57b) and dirtying (58b) different things.

$$
\begin{array}{ll}
\text { a. } & \llbracket(\mathbf{5 5 b}) \rrbracket^{o}=\lambda d \lambda e\left[\operatorname{ag}(m, e) \& \text { straight }_{\Delta}(h, d, e)\right] \\
\text { b. } & \llbracket(\mathbf{5 5 b}) \rrbracket^{f}=\left\{\lambda d \lambda e\left[\operatorname{ag}(m, e) \& \operatorname{straight}_{\Delta}(x, d, e) \mid x \in D_{e}\right\}\right. \\
\text { a. } & \llbracket(\mathbf{5 6 b}) \rrbracket^{o}=\lambda d \lambda e\left[\operatorname{ag}(m, e) \& \operatorname{dirty}_{\Delta}(t, d, e)\right] \\
\text { b. } & \llbracket(\mathbf{5 6 b}) \rrbracket^{f}=\left\{\lambda d \lambda e\left[\operatorname{ag}(m, e) \& \operatorname{dirty}_{\Delta}(x, d, e) \mid x \in D_{e}\right\}\right.
\end{array}
$$

The relative reading arises in connection with the focus alternatives in $(57 b, 58 b)$. Comparison class $X$ is a subset of these sets. Under this approach, it suffices that the hair's change in straightness was greater than the change in straightness of anything else (56) and that that table's change in dirtiness was greater than the change in dirtiness of anything else (56). Thus, a maximum need not be reached, as long as the degree (of change) to which the hair was straightened or that table was dirtied is greater than any other degree to which any other thing was straightened or dirtied. ${ }^{9}$

9 Although the main focus of this paper does not reside in an account of the telicity contrasts discussed in section 3 , it is worth pointing out that the proposal put forward in this section is compatible with 
Martínez Vera

\section{Conclusion}

This paper has made the novel observation that Southern Aymara has a verbal superlative, namely, the suffix $-s u$, that combines with degree achievements-for illustration, I focused here on degree achievements derived with the suffix -cha. I have shown that the ambiguity attested in the literature addressing adjectival superlatives between an absolute and a relative reading is also present in the Aymara cases involving -su. More generally, this paper has argued that there is a relevant notion of superlatives beyond the adjectival domain by focusing in the verbal domain. The proposal in this paper constitutes an initial attempt to characterize verbal superlatives, which I have stated in terms of comparison of degree-event pairs. I have further shown how the absolute reading of verbal superlatives arises under this approach: a degree of change to the maximum is reached in an event and this degree is not reached in any of the events in the relevant comparison class. The relative reading of verbal superlatives arises when there is interaction with focus; I discussed cases with a focalized external and internal argument. In the presence of a focalized argument, a maximum need not be reached in the event (as long as the relevant degree of change exceeds the degree(s) reached in the events in the comparison class determined by the focalized arguments).

\section{References}

Bierwisch, Manfred. 1989. The semantics of gradation. In Manfred Bierwisch \& Ewald Lang (eds.), Dimensional adjectives, 71-262. Berlin: Springer.

Bochnak, M. Ryan \& Lisa Matthewson (eds.). 2015. Methodologies in Semantic Fieldwork. Oxford: Oxford University Press.

Cerrón-Palomino, Rodolfo. 2008. Quechumara: Estructuras paralelas del quechua $y$ del aimara. La Paz: UMSS, PROEIB Andes, Plural editores.

Cresswell, M. J. 1976. The semantics of degree. In Barbara Partee (ed.), Montague Grammar, 261-292. New York: Academic Press.

Davis, Henry, Carrie Gillon \& Lisa Matthewson. 2014. How to investigate linguistic diversity: Lessons from the Pacific Northwest. Language 90(4). 180-226. doi: 10.1353/lan.2014.0076.

Farkas, Donka F. \& Katalin E. Kiss. 2000. On the comparative and absolute readings of superlatives. Natural Language and Linguistic Theory 18(3). 417-455. doi: 10.1023/A:1006431429816.

such contrasts, specifically, in the cases in which -su is present. In particular, my account states that a bound in an event is reached, since a degree that exceeds any other degree in the relevant comparison class is reached (see Martínez Vera 2018 for further discussion). 
Superlatives across domains

von Fintel, Kai. 1994. Restrictions on quantifier domains: University of Massachusetts Amherst dissertation.

Gonzalo Segura, Roger. 2011. La derivación verbal en el aimara de Pomata: Pontificia Universidad Católica del Perú MA thesis.

Hay, Jennifer, Christopher Kennedy \& Beth Levin. 1999. Scalar structure underlies telicity in "Degree achievements". Semantics and Linguistic Theory (SALT) 9. 127-144. doi: 10.3765/salt.v9i0.2833.

Heim, Irene. 1985. Notes on comparatives and related matters. Ms., University of Texas Austin.

Heim, Irene. 1999. Notes on superlatives. Ms., Massachusetts Institute of Technology.

Instituto Nacional de Estadística e Informática. 2010. Censos de Población y Vivienda 2007. http://ineidw.inei.gob.pe/ineidw/.

Kennedy, Christopher. 2007. Vagueness and grammar: The semantics of relative and absolute gradable adjectives. Linguistics and Philosophy 30(1). 1-45. doi: 10.1007/s10988-006-9008-0.

Kennedy, Christopher \& Beth Levin. 2008. Measure of change: The adjectival core of degree achievements. In Louise McNally \& Christopher Kennedy (eds.), Adjectives and adverbs: Syntax, semantics and discourse, 156-182. Oxford: Oxford University Press.

Kennedy, Christopher \& Louise McNally. 2005. Scale structure, degree modification, and the semantics of gradable predicates. Language 81(2). 345-381. doi: 10.1353/lan.2005.0071.

Klein, Ewan. 1991. Comparatives. In Arnim von Stechow \& Dieter Wunderlich (eds.), Semantik: Ein internationales Handbuch der zeitgenössischen Forschung, 673-691. Berlin: Walter de Gruyter.

Klose, Claudius. 2015. Sentence type and association with focus in aymara. In Mood, Exhaustivity \& Focus Marking in non-European Languages, 63-86. Potsdam: Universitätsverlag Potsdam.

Kratzer, Angelika. 1996. Severing the external argument from its verb. In Johan Rooryck \& Laurie Zaring (eds.), Phrase structure and the lexicon, 109-137. Dordrecht, The Netherlands: Kluwer Academic Publishers.

Martínez Vera, Gabriel. 2018. On competing degree morphemes in verbs of change in Southern Aymara. Sinn und Bedeutung (SuB) 22. 125-142.

Matthewson, Lisa. 2004. On the methodology of semantic fieldwork. International Journal of American Linguistics 70. 369-415. doi: 10.1086/429207.

Merchant, Jason. 2015. How much context is enough? Two cases of spanconditioned stem allomorphy. Linguistic Inquiry 46(2). 273-303. doi: 10.1162/LING_a_00182. 
Morzycki, Marcin. 2015. Modification. Cambridge, UK: Cambridge University Press.

Pancheva, Roumyana \& Barbara Tomaszewicz. 2012. Cross-linguistic differences in superlative movement out of nominal phrases. West Coast Conference on Formal Linguistics (WCCFL) 30. 292-302.

Pedersen, Walter A. 2015. A scalar analysis of again-ambiguities. Journal of Semantics 32(3). 373-424. doi: 10.1093/jos/ffu003.

Rooth, Mats. 1992. A theory of focus interpretation. Natural Language Semantics 1(1). 117-121. doi: 10.1007/BF02342617.

Rooth, Mats. 2016. Alternative Semantics. In Caroline Féry \& Shinichiro Ishihara (eds.), The Oxford Handbook of Information Structure, 19-40. New York: Oxford University Press.

Sharvit, Yael \& Penka Stateva. 2002. Superlative expressions, context, and focus. Linguistics and Philosophy 25(4). 245-265. doi: 10.1023/A:1020875809794.

Stateva, Penka. 2002. How different are different degree constructions?: University of Connecticut dissertation.

von Stechow, Arnim. 1984. Comparing semantic theories of comparison. Journal of Semantics 3. 1-77.

Szabolcsi, Anna. 1986. Comparative superlatives. In Naoki Fukui, Tova Rapoport \& Elizabeth Sagey (eds.), MIT Working Papers in Linguistics, vol. 8, 245-266. Cambridge, MA: MIT Press.

Tomaszewicz, Barbara M. 2015. Superlative ambiguity: A comparative perspective: University of Southern California dissertation.

Gabriel Martínez Vera

Department of Linguistics

OAK Hall, Room 368

365 Fairfield Way, Unit 1145

Storrs CT 06269-1145, USA

gabriel.martinez_vera@uconn.edu 